\title{
Sobre los estudios de historia intelectual y la temática de las independencias
}

Um dos maiores estudiosos do século XX sobre a história do pensamento e cultura argentina, José Carlos Chiaramonte é professor honorário da Universidade de Buenos Aires e Investigador do Conselho de Investigações Científicas y Técnicas da Argentina (CONICET).

Ao longo de sua trajetória acadêmica, que conta com mais de meio século de atividades, Chiaramonte publicou diversos livros, artigos e capítulos; referências obrigatórias para estudiosos sobre política e ideias na América latina, com destaque para o período de formação dos Estados Nacionais. Seus temas de pesquisa também perpassam pelo debate dos fundamentos intelectuais e políticos das independências iberoamericanas e pela ilustração na Iberoamérica. Merecem destaque dentre outros trabalhos: Raíces históricas del federalismo latinoamericano (2016); Usos Políticos de la historia. Lenguaje de clases y revisionismo histórico. (2013); Cidades, Provincias, Estados: Origens da Nação Argentina (1800-1846) (2009); Nación y Estado en Iberoamérica. El lenguaje político en tiempos de las independencias (2004); Biblioteca del pensamiento argentino con Tulio Halperín Donghi (1995); La Ilustración en el Río de la Plata, Cultura eclesiástica y cultura laica durante el Virreinato (1989).

Entrevista com o professor José Carlos Chiaramonte realizada pelas professoras doutoras Érica Sarmiento (UERJ) e Marieta Pinheiro de Carvalho (UERJ) e pelo pesquisador Celso Louzada (UERJ/Faperj) em 10 de abril de 2019, durante o II Colóquio Internacional Movimentos, Trânsitos e Memórias. 

José Carlos Chiaramonte (JCC): Trataré de hacer una síntesis que, como todas síntesis, son cosas incompletas. Lo que a mí me pregunto, de la historia intelectual, es que generalmente la hemos hecho, yo incluido, como una historia de las influencias de grandes pensadores de cualquier campo que fuese a lo largo de la historia, una historia de las grandes corrientes de pensamiento, una historia de su recepción en cada lugar y temas, como vinculados a esto ¿no?, a una historia de las corrientes de pensamiento y que, obviamente, nos llevan al plano más alto de la producción intelectual, producción de los grandes autores. Pero, de repente, me di cuenta de dos cosas, que retomando una vieja pretensión que había abandonado porque era excesiva, y que he retomado tratando de manejarla en parte, que es hacer... no hacer una especie de historia económica, historia política, sino tratar de hacer, de contemplar una historia en su conjunto. Aunque individualmente yo no pueda abarcar el conjunto de ese conocimiento, sí, puedo tratar de conectar lo que hacen otros a lo que hago yo, en función del problema central que es la historia, la historia a seca. Entonces, me di cuenta que lo más importante para la historia intelectual era la creencia, las ideas que la gente tenía en la cabeza mientras convivía en el seno de la sociedad y mientras hacía política en esa sociedad, es decir, ¿qué tiene la gente en la cabeza? Voy a tomar un ejemplo muy rápido: un diputado en un congreso constituyente puede darse lustre importancia citando al último intelectual europeo de moda, ya sea, Rousseau, Benjamin Constant, o quien fuera, pero después, en la práctica, adhería a la implantación de dictaduras, como soluciones mescladas con el régimen representativo que suponemos que existía en ese lugar. Es decir, se trataría de una historia intelectual, lo que, como lo explico en mi libro Fundamentos intelectuales y políticos de la independencia (2010), una historia intelectual profunda, cuáles son las ideas, creencias, pautas que conviven en diferentes grupos humanos en el momento en que actúan y eso nos puede dar una cosa muy diversa. Por ejemplo, cuando yo empecé a trabajar sobre la formación de los estados rioplatenses, luego latinoamericanos, más tarde lo hice sobre otros lugares de América Latina. El nombre de Vattel me era absolutamente desconocido, Vattel con "v" corta. Sin embargo, es el autor de mayor importancia, desde Massachusetts, de Boston, digamos, hasta Buenos Aires, al fin del siglo XVIII y a comienzos del siglo XIX, pasando por Brasil, lógicamente. Sin embargo, ni yo ni ningún de mis colegas, ni siquiera François Xavier Guerra, ni siquiera grandes historiadores, Tulio Halperín Donghi, puedo decir, había prestado ninguna atención a Emer de Vattel. Y entonces aquí tenemos un problema serio: ni les hemos 
prestado mucha atención a los nombres de esta historia intelectual proveniente de la historia de la filosofía y de la historia política, sin atender a lo que la gente utiliza ¿Por qué Vattel? Porque era autor de un tratado de derecho de gentes, que como dijo un publicista inglés a fines del siglo XVIII, la ciencia del laboral y la política hoy, entre nosotros, se llama derecho natural de gentes. El derecho natural, considerado solamente como una rama del derecho, a fines del siglo XVIII y comienzos del XIX era, en realidad, la ciencia de la sociedad, y esto nos da un panorama completamente distinto de lo que era la teoría intelectual hasta el presente.

\section{Comentar acerca de los conceptos importantes para el lenguaje político de la época de la independencia y por qué Usted considera el concepto de soberanía central para entender ese período.}

JCC: Aquí es el tema con el cual suelo discutir con algunos colegas, muy buenos historiadores en Buenos Aires, en Argentina. Creo que han pagado demasiados tributos a la moda, a las modas intelectuales que son un peligro para toda la vida intelectual. Yo podría contar aquí la cantidad de modas que han pasado y que han desaparecido. Modas intelectuales como Althusser, por ejemplo, la peste althusseriana, como suelo decir; Foucault, etc., etc. Yo creo que hay una de las modas que provienen de la influencia de la buena historiografía anglosajona que es la prioridad concedida a los problemas del liberalismo y republicanismo, que son importantísimos, pero en América Latina hay un problema mucho más importante que para Europa lo señaló Norberto Bobbio, el famoso teórico, jurista y politólogo italiano: el gran problema de la gran moderna europea es el problema de la soberanía, es decir, el problema cómo quitarle el poder a los sectores que tenían retazo, que ejercían retazos de soberanía, las ciudades, los gremios, las órdenes religiosas, etc.. Y de manera a quedar una sola, un solo ente soberano que es el estado nacional.

Entonces este problema, según señaló Bobbio, dio origen a conflictos muy sangrientos, inclusive en la historia europea. Es decir, en otras palabras, cómo terminar con el poder de los poderes sin tener el poder de la soberanía de los poderes intermedios y cómo unificar en una sola soberanía la organización política. Este es el gran problema. Voy a usar un ejemplo argentino. En Argentina, en el siglo XIX, el conflicto más famoso era 
entre unitarios y federales, o sea, que, desde la historia, la literatura, pasando por la música también. Por ejemplo, una de las figuras musicales más importantes del folclore argentino es la zamba, hay una zamba unitaria y una zamba federal. En que me acuerdo mis colegas y amigos me preguntaban: ¿qué es esa zamba de ese que dice "matando viene y se va"? Es la figura del caudillo sangriento que viene matando, esa es la zamba anti unitaria. La zamba federal era Felipe Varela. Entonces, y sin embargo, ni Halperín Donghi le ha prestado importancia. Halperín no le prestó ninguna atención al fondo político, ideológico, de la oposición unitaria federal, y más bien la trató siempre como un conflicto faccioso, en el plano de las guerras, no se indagó sobre la diferencia entre estado federal y confederación, que es lo que explica justamente. Entonces de ahí que el problema de soberanía lo considero un problema central, es decir, bajo el rótulo del federalismo, ocultamos algo que no es federalismo que, en el lenguaje político de hoy, no es federalismo, sino es confederación. Pero, ¿qué sucede? Para las historiografías nacionales, nacionalizantes, de cada país, si se reconoce que lo que llamamos provincias, no eran tales, sino eran estados soberanos, se acaba el mito, como lo intitulé en uno de mis trabajos, El mito de los orígenes (1993), de una nacionalidad persistente a la independencia. Entonces, todavía hoy, importantísimo, porque historiadores de Argentina, México y de Brasil también, no quieren reconocer que el federalismo de aquella época, era otra cosa, no era el federalismo, sino confederación. Que las rebeliones de San Pablo, y de otros lugares en la primera mitad del XIX, eran de otra naturaleza, no eran federales, tenían todavía un resabio de las tendencias, de la defensa de la soberanía local, todavía un estado monárquico.

\section{¿Cuáles las implicaciones de este análisis de la soberanía que Ud. considera importante para el desarrollo de una nueva historia intelectual-política de Iberoamérica?}

JCC: Nos obliga a tomar consciencia de que mientras circulaba en los periódicos, en las reuniones, en las asambleas legislativas, en las asambleas constitucionales, es la cita de prominentes intelectuales europeos y norteamericanos. En la práctica la gente se movía con la mescla de ideas, y yo digo mescla, ¿por qué? Reconozco esa mescla de ideas que tenía otras fuentes y, a veces, fuentes muy distantes. El que mejor comprendió esto, el 
que mejor comprendió la importancia de las ideas, en la realidad histórica, porque muchas veces uno explica la teoría demás y los alumnos igual le pueden preguntar: "pero, bueno, esto son justificaciones, es retórica..." pero no. Las ideas son fuerzas históricas importantísimas.

\section{¿Es posible se pensar el fenómeno de las independencias en América a partir de una perspectiva comparada? Y, ¿cuáles son los acercamientos posibles?}

JCC: Bueno, la perspectiva comparada es imprescindible para todo nuestro trabajo. Esta es una percepción que tenía en Argentina y que se me hizo mucho más fuerte en los diez años que viví en México, donde la tendencia era trabajar el pequeño recorte geográfico. Recuerdo que una vez un alumno dijo allá: "Pero, ¿por qué tanta historia egipcia, además? ¿Por qué necesitamos historia del ajeno? Con la nuestra nos basta.”. Bueno, entonces, la historia comparada es imprescindible para comprender mejor nuestra historia, es decir, ¿para qué quiere comprender mejor? Por ejemplo, las reformas liberales. En Argentina alrededor de 1880: registro civil, enseñanza laica, etc... reformas hechas por líderes llamados "liberales", entre comillas. En Ecuador com un dictador, católico, tramontano se daban las mismas reformas. Entonces la obliga a reinterpretar qué es lo que está sucediendo: en toda América se están dando procesos similares bajo distintos signos ideológicos. No todos los gobiernos adoptaron el régimen federal, y esto es una invención norteamericana, es imprescindible ver como lo aplicaron allá y porque hay los mismos regímenes representativos. El problema era que, en los pueblos ocurre así: toman la iniciativa de algunos momentos para los cuales no hay las menores condiciones y hay que ver como se adaptan a iniciativas de otros lugares, y hay que ver si se la pueden adoptar o no, cosa que en América Latina no ocurrió totalmente ni mucho menos. Entonces hoy la gente se desgasta diciendo por qué nuestras democracias tienen tantos problemas. Bueno, creo que venimos alastrando problemas serios desde el comienzo.

Los padres fundadores (Estados Unidos), Madison, Jefferson y otros, querían que a los órganos representativos llegara gente más capaz y moralmente más seria. Pero tenían una oposición en la asamblea de los estados (pero eso son discusiones previas a la de 
Filadelfia), creo que la de Virginia, en que había líderes populares que los otros calificaban de aventureros, entre los maestros y los artesanos. La esencia de la democracia americana consiste en que nosotros podamos llevar nuestros intereses a los órganos representativos. Cosa que nosotros en América Latina consideramos inmoral: ¿cómo los diputados van a estar defendiendo intereses particulares? Y después nos sorprendemos de lo que ocurre en el congreso de los Estados Unidos. Bueno, según Gordon Wood, eso triunfó, esa es democracia norteamericana que para él es un desastre, pero que, por suerte, según él, la única defensa posible es la reserva federal, es decir, el Banco Central, que puede imponer límites a las pretensiones económicas del ilegítimo. Bueno, son diferencias muy grandes, que son imprescindibles comparar porque hemos adoptado sistemas políticos que no nacieron aquí en América Latina.

\section{En algunos de sus estudios resalta que las naciones fueron consecuencias} de las independencias, no su causa, que no había identidades nacionales, argentina, mexicana, colombiana, antes del siglo XIX, trabajando con aspectos de la naturaleza confederal de las primeras organizaciones políticas independientes. ¿Podrías hablar algo más acerca de eso?

JCC: El gran descubrimiento que empezó a hacerme cambiar la perspectiva sobre la historia, primero argentina del siglo XIX, porque luego empecé a compararla con otros lugares de la América Latina, y cuando de la UNESCO me pidieron un trabajo sobre los poderes regionales de toda América, tuve que completarla y las informaciones más ricas venían de los historiadores antiguos, porque los nuevos están más influidos por las corrientes de moda y los otros reflejaban las cosas que realmente ocurrían. Entonces, lo primero que descubrí que nosotros explicábamos las independencias como frutos de identidades nacionales. Cosa que es una barbaridad porque la mayor parte de los historiadores demuestran como las principales naciones europeas en momentos de constituirse con su forma de estado actual eran multiétnicas, ya sea Francia, Inglaterra, etc. Entonces, me he dado cuenta que este esquema sobre la legitimidad de un estado fundado no en la nacionalidad, era un mito ideológico del romanticismo que, por ejemplo, en la Argentina entró con la generación del 37, mucho más tarde. Que, en 1810, si uno toma el primer diccionario de la Academia, diccionario de autoridad, de la 
Academia Española, nacionalidad era simplemente la pertenencia a una nación, no esta idea de comunidad. Siempre existieron en la historia grupos humanos, culturalmente homogéneos y con consciencia de esa homogeneidad, pero nunca se le agregó a eso la pretensión de ser estado independiente. Esa es la novedad del siglo XIX. Es decir, tú tienes una monarquía absoluta, donde hay inclusive reinos con sus propias instituciones, ciudades con sus propias autonomías, soberanía e instituciones, etc., una colección, ya sea en España, en Portugal, ya sea en la actual Alemania, pero ninguna de esas partes componentes tenía pretensiones de vivir independientemente, salvo alguna excepción. Este siglo que a partir de los escritores del amor romántico inventa las nociones de pueblo, de nación, nacionalidad, etc. y destruía o desacreditaban que eso existiera. La autoridad monárquica hay que reemplazarla, es decir, como un gobierno puede mandar a matarse a la gente a una guerra que antes hacía en función de su rey, si ahora ya eso no funciona. Tiene que haber alguna lealtad que la suplante a la ley de la monarquía y esa lealtad es la nación. Entonces, la legitimidad de un estado lo explica un sacerdote. Hacer una nación consiste en que yo pongo algo en beneficio común y quiero saber qué ponen los otros en beneficio mío, etc. Es decir, una noción racional. Los sentimientos pueden ayudar a fortalecer la lealtad a un estado, a un monarca o lo que sea, pero la legitimidad política no se funda en la nacionalidad, en la consciencia de la nacionalidad, sino en un acto racional fundado en el principio que es fundamental en toda la historia europea de todos tiempos, que es el principio del consentimiento. Nadie me puede obligar a entrar en una asociación política sin mi consentimiento y si yo quiero salir de esa asociación tengo derecho a salir.

La gran parte de los conflictos políticos del XIX latinoamericanos vienen por eso: las élites locales, sobre todo en las ciudades, las antiguas capitales del reino, como se decía en Buenos Aires, que quieren hacer estados centralizados y obligar a que todos puedan entrar y sí a los pueblos que dicen no, nosotros vamos a entrar por libre consentimiento y esto es una gran excusa que usa Buenos Aires en 1860. Buenos Aires no entró a la República Argentina en 1853. ¿Por qué? Porque por libre consentimiento no aceptó las condiciones y se formó como se declaró entre el 1853 y el 60 vivió como estado independiente y soberano. Mientras tanto, Argentina tenía un nombre erróneo: Confederación Argentina, porque había dejado de ser confederación y ya era un estado federal. Pero, los líderes, ex confederados como Urquiza vencedor de (Juan Manuel de) Rosas, por no quedar mal con sus próceres que venían de aquel lado, mantuvieron esto. 
Si Ustedes me preguntan cuál es mi nacionalidad. Yo puedo contestarles: yo soy provinciano del Reino Unido del Río de La Plata, yo soy confederacionista argentina o yo soy argentino. Porque el artículo 35 de la reforma de 60 cuando votó incluso a Buenos Aires habilita cualquiera de estos tres nombres, serán nombres oficiales de la República Argentina, pero en los documentos oficiales se le usa dar la expresión "Nación Argentina". Lo que se usó sin embargo fue República Argentina, por una cuestión de práctica de documento, pero el otro artículo sigue válido, de manera que yo siempre sorprendo al auditorio diciendo yo soy Provinciano Unido del Río de la Plata. Ahora, ¿por qué eso? Empieza por el general Urquiza, vencedor de Juan Manuel de Rosas, vencedor de Buenos Aires en una batalla, entonces Buenos Aires resolvió entrar por libre consentimiento, pero para eso exigió una convención constituyente, una asamblea constitucional de Buenos Aires para revisar la constitución. La palabra de orden ahí en esa asamblea era "consentimiento". Buenos Aires va a entrar por libre consentimiento, es decir, lo que pasaba era que Argentina había fracasado económicamente, sin Buenos Aires no tenía perspectiva, por eso tuvo que hacer entrar a Buenos Aires. Urquiza dio la orden de conceder todas las exigencias de Buenos Aires, salvo una: que el país no se va a llamar como querían los porteños Provincias Unidas del Río de la Plata.

Toda su obra es una referencia para lo que sería la historiografía de América Latina, principalmente en relación al mito de los orígenes de las naciones. ¿Cómo Ud. analiza los nuevos estudios y la contribución de la historiografía actual en relación a esa cuestión?

JCC: Lo que yo he trabajado tiende a explicarse el tema del origen de las naciones, pero hay otros temas historiográficos que tienen una relación más distante con esos que son válidos. El problema es que todo eso debería pensarse integrado en una sola historia, porque solamente estudiar un proceso económico de diez años despegado del gran problema que es la historia de un país o de una región, y eso es un problema difícil de responder para el cual, probablemente, no hay respuesta falsa. 


\section{Ud. es considerado como un pionero en los estudios de historia regional, ¿cómo se inicia eso?}

JCC: Bueno, sí, fui un pionero sin pretenderlo, sin darme cuenta porque es una historia así: se refiere a lo que después fue mi libro Mercaderes del Litoral: economía y sociedad en la Provincia de Corrientes entre 1820-1840 (1991). Cuando del golpe de estado de Onganía en Argentina, los profesores de la Universidad de Rosario quedaron sin trabajo y me pidieron para seguir trabajando en un seminario que yo coordinaba, privado, sobre un estudio sobre el Río de La Plata a fines del siglo XIX, y alguien vino un día (así empiezan los grandes descubrimientos) diciendo que había descubierto un archivo muy rico en la ciudad de Corrientes. Fuimos a explorarlo y yo ya había publicado mi libro Nacionalismo y liberalismo económico en Argentina 1860-1880 (1971), donde había estudiado un movimiento del nacionalismo económico, de proteccionismo. Y justamente el líder de Corrientes, Pedro Ferré que se exilió un tiempo en San Borja, del otro lado de Uruguay, de río Uruguay, donde escribió sus memorias, tenía un programa de desarrollo industrial protegido. Entonces vamos a ver si encontramos algunas vinculaciones entre ese proyecto de los años 30, peleando contra el liberalismo de Buenos Aires y el liberalismo de Rosas porque en política económica Rosas es absolutamente libre cambista por el tratado de amistad y libre navegación con Inglaterra que defendió a muerte porque era la base de la propiedad en Buenos Aires. Entonces, empezamos a trabajar con el archivo de Corrientes. De repente empecé a descubrir que esta provincia era más bien un estado. Todo está contado en el libro y se fue enhebrando una investigación. Yo me mudé de Rosario, desde donde había hecho viajes, a Corrientes, a Bahía Blanca, a la Universidad del Sur, donde estuve tres años. Con fondos de la Universidad del Sur viajé al archivo de Corrientes a seguir la investigación. Al tenerme que exiliar en México, después de ganar un subsidio de la asociación de la Universidad de Wisconsin, para continuar con los estudios en Corrientes, ocurrió una cosa curiosa: logré pagar a ayudantes que se habían quedado en Argentina que fueran al archivo buscando información y cuando con la caída de los militares, empecé a viajar a Argentina, antes volver. El primer viaje que hice fue al archivo de Corrientes, seguí volviendo y cuando volví a Argentina, esto fue en el 1983, cuando volví a Argentina al final del 85, traía el Mercaderes del litoral casi todo terminado. Resulta un libro de historia regional, un libro que todo el mundo apreciaba, sobre todo los historiadores del interior, porque no era un libro hecho desde la 
perspectiva de Buenos Aires, sino de la perspectiva de la historiografía lugareña, folclórica, pensada por historiadores locales. En el archivo de Corrientes, por ejemplo, la correspondencia política estaba muy manoseada y los documentos económicos estaban impecables, estaban intocados y la contabilidad pública era un ejemplo. En Corrientes había tres libros y cada uno, a veces tenía dos o tres copias y bien prolijamente, y bien encuadernados, en una contabilidad que no era de partida doble como se usa actualmente, porque la partida doble se intentó aplicar en Hispanoamérica por orden real y fracasó porque nadie la entendía. Entonces, entradas, salidas, cambio, data, esa era la contabilidad, una columna para la entrada, otra columna para la salida y tres libros: mayor, diario y mayor, diario y el otro ya no me acuerdo. Eran impecables, no eran ni usados. Bueno, entonces eso se convirtió en un trabajo de historia regional en el cual yo estaba utilizando lo que había aprendido de la época en que frecuenté la cátedra de José Luis Romero.

\section{Referências bibliográficas}

CHIARAMONTE, José Carlos. (2010) Fundamentos intelectuales y políticos de las independencias: Notas para una nueva historia intelectual de Iberoamérica. Buenos Aires: Teseo.

. (1993). El mito de los orígenes en la historiografía latinoamericana. Instituto de Historia Argentina y Americana Dr. Emilio Ravignani, Facultad de Filosofía y Letras, Universidad de Buenos Aires.

(1991). Mercaderes del litoral: Economia y sociedad en la provincia de Corrientes, primera mitad del siglo XIX. San Diego. Fondo De Cultura Economica USA.

. (1971). Nacionalismo y liberalismo económicos en Argentina, 1860-1880. Buenos Aires: Solar/Hachette.

Artigo recebido em: 20 de julho de 2021.

Artigo aprovado em: 20 de setembro de 2021.

DOI: 10.12957/intellectus.2021.63950 